\title{
A contextual effect in feature detection with application of signal detection methodology
}

\author{
MARCUS WOMERSLEY \\ University of British Columbia, Vancouver, B.C., Canada
}

\begin{abstract}
These experiments address the question of whether the perception of a form is exclusively determined by a prior analysis of its elements. Employing a signal detection task, Experiment 1 replicated the finding of Weisstein and Harris (1974) that embedding a line segment feature in a unitary figural context facilitates its detection. The results of Experiment 2 suggest that the most probable agent of this context effect on feature detection is the three-dimensionality of the unitary context. With bi-hemiretinal stimulus presentation. Experiment 3 showed a significant context effect in the right, but not in the left visual field. Some current paradigms are applied to these results.
\end{abstract}

Of the attempts to analyze the processes by which we come to visually perceive a form, a salient paradigm is the information-processing approach, which seeks to analyze perception into a set of elements, regarded as processes of information transformation (Haber \& Hershenson, 1973).

Pandemonium-type models. of information processing (Neisser, 1967; Selfridge, 1959) have gained much impetus from the pioneering physiological work of Hubel and Wiesel $(1962,1965,1968)$. On the basis of single-cell recordings and the putative functional architecture of the mammalian cortex, they present a "possibly over-simplified concept" (1968) of a hierarchic system of receptive fields dependent on anatomical wiring.

This work has been taken to provide an explanation of how information is processed in the human visual system (see Sekuler, 1974). Under the usual seriality assumption (Sekuler, 1974), elementary features, on this view, are detected in the processing hierarchy as a precondition of the perception of organized structure or pattern. According to this approach, the perception of the whole is subsequent to and dependent on an analysis of its parts.

If this linear causation view is correct, a manipulation of the context pattern in which an elementary feature is embedded should not affect the detectability of the feature. Weisstein and Harris (1974) found that the detection of a line segment oriented in the visual field is facilitated if it is within a unitary context. Experiment 1 was an attempt to replicate this finding, using a tachistoscopically presented signal detection task; Experiment 2 was an attempt to analyze the pertinent aspects of the unitary pattern

This research formed part of a thesis accepted in partial fulfillment of the requirements for a Master's degree in psychology at the University of British Columbia, and was supported by Grant A9958 from NRC of Canada to L. M. Ward. I thank Larry Ward and Stanley Coren for their assistance; also Irwin Pollack and two anonymous reviewers for critical readings of earlier drafts. in producing the effect; and in Experiment 3, the intention was to relate any findings of a contextual effect to the burgeoning literature on functional cerebral hemispheric dominance.

\section{EXPERIMENT 1}

This experiment was intended to improve on the design of Weisstein and Harris (1974). The detectability of a line segment was tested under two conditions of context, unitary and nonunitary. Every attempt was made to equate the unitary and nonunitary stimuli on the number of lines constituting the pattern, their area, and the position and orientation in the observer's visual space of both the whole pattern and the target line.

The measure of detectability was derived through signal detectability theory (Nachmias, 1974). For this experiment, the usual restrictive assumptions of normality and variance homogeneity seemed unjustified, and a nonparametric index of detectability, E, was used (Simpson \& Fitter, 1973). Two $E_{i}$ were derived for each subject; this yielded a measure of the subject's ability to detect the target in both a unitary and a nonunitary context. In addition, each subject made confidence ratings.

\section{Method \\ Subjects. The subjects were 10 members of the university community, 8 females and 2 males, all adults. All had normal or corrected vision and all volunteered for the experiment, which comprised one session of approximately $\mathbf{4 0} \mathrm{min}$. \\ Apparatus. The four stimuli were based on, but incorporated some changes from, those used by Weisstein and Harris (1974). They are shown in Figure 1. They were drawn on white cards and within $2.5 \mathrm{deg}$ visual angle of a fixation point (Figure 2), so that vision was predominantly foveal. Each stimulus contained one target line, oriented either (up to the) left or right at a 45-deg angle from the vertical. All stimuli, unitary $\left(C_{1}\right)$ or nonunitary $\left(C_{2}\right)$, comprised the same set of elements-six one-unit lines, two half-unit lines, and a dot, in addition to the target line. The fixation point with masking surround was made in a similar}




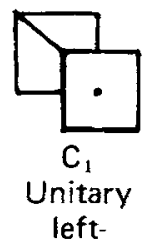

oriented

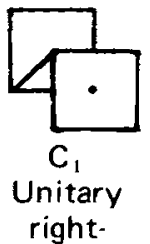

oriented

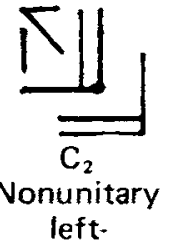

oriented

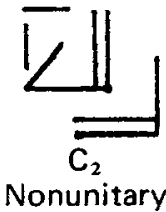

right-

oriented
Figure 1. Stimuli for the signal detection task-Experiment 1.

fashion (Figure 2); the masking stimulus was to reduce the availability of the icon, so that performance would not be a function of a subject's capacity for visual imagery. The fixation point was located where the target line meets the corner of the lower square $\left(C_{1}\right.$, Figure 1$)$.

The stimuli were presented in a Gerbrands two-channel tachistoscope. The fixation point was in Field 1; the stimuli were presented in Field 2, and designed such that, for the left-oriented targets, the target line segments and contexts were in the same position in relation to the fixation point and covering the same area in the visual space. This also held for right-oriented targets.

Procedure. The experiment was carried out in a dimly illuminated room, and at the start of each session the subject was dark-adapted for approximately $10 \mathrm{~min}$. Instructions were followed by practice trials, during which exposure times were manipulated until the subject was responding with approximately $70 \%$ accuracy. The tachistoscopic presentation time (the same for all stimuli) was thus brief enough to ensure an adequate degree of "noise" for the signal detection task, and also to effectively rule out saccadic eye movements. Saceadic reaction time is about $200 \mathrm{msec}$, while, for this study, exposure times were between 17 and $44 \mathrm{msec}$. The importance of fixating after the "ready" was emphasized, and no subject reported any difficulty in so doing. The moderate level of illumination of the stimuli and the fixation point (the same for each) was constant for all subjects under all conditions. The fixation point was on constantly, except during the brief exposure of the stimulus. Thus, for each trial, the subject would be told to "fixate"; the response of "ready" would be followed, after a brief indeterminate pause, by one of the target stimuli which would replace the fixation point in the subject's visual space, to be replaced in turn by the fixation point and its surround, which was large enough to mask the target stimulus. The subject then verbalized a decision on the direction of the target line segment and gave a confidence rating. Each of the four stimuli was presented on 24 trials for a total of 96 trials, done in irregular order, for each subject.

\section{Results}

For each context, $C_{i}$, the number of responses under the ratings was summed, then the sums accumulated to get a cumulative distribution; by the selection of the left target line orientation as "signal"

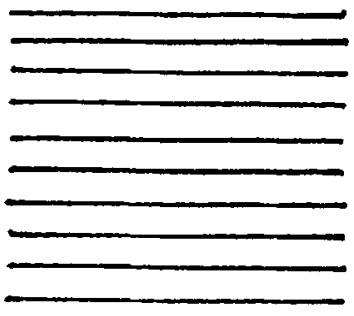

Figure 2. Fixation point. (the right then being "noise"), this becomes the familiar receiver operating characteristic (ROC) curve. The accumulation over confidence ratings of responses to a left-oriented target line therefore corresponds to the "hit rate," while the "false alarm rate," in the usual terminology, is given by the accumulation of responses to a right-oriented target.

Table 1 shows the group means for the index of detectability under the two conditions. This index is given by

$$
E=\left(\bar{X}_{L}-\bar{X}_{R}\right)\left[2 /\left(s_{L}^{2}+s_{R}^{2}\right)\right]^{1 / 2},
$$

where $\bar{X}_{L}$ and $\bar{X}_{R}$ are the means of the grouped data for left-oriented and right-oriented targets, respectively, and $s_{\mathrm{L}}^{2}$ and $s_{\mathrm{R}}^{2}$ are the variances. As a nonparametric index, $E$ is equivalent to the $R O C$ subjacent area.

A t test for correlated means was performed on the $\mathrm{E}_{\mathrm{i}}$. For $\mathrm{N}=10, \mathrm{p}(\mathrm{t}=3.013)<.05$, a significant difference, indicating a strong contextual effect on the discriminability of the target line segments. This replicates the finding of Weisstein and Harris (1974). The perception of a form does not seem to be determined exclusively by the prior analysis of its elements, since, under the conditions of the experiment, the latter apparently depends on the former.

\section{EXPERIMENT 2}

The unitary stimuli of Experiment 1 contained a superposition cue and a dot giving them a fairly convincing three-dimensional appearance. In Experiment 2 , a differentiation was made between unitary and three-dimensional information to discover if the latter was a factor in the contextual effect on feature detection, or whether a unitary context alone was sufficient. As in the previous experiment, the discriminability of a target line segment feature was tested under two conditions-a unitary and a nonunitary context. Again, the target feature was a line segment oriented at a 45-deg angle; the unitary figure was designed to minimize depth information, and to be interpreted as two-dimensional. To this end, both the superposition cue and the dot were omitted. Also, the stimuli were designed to be equivalent in such properties as number of constituent line segments, area, and position and orientation in the observer's visual space. A signal detection task was employed, and conditions were generally as those of Experiment 1.

\section{Method}

Subjects. The subjects were 10 members of the university community, 9 females and 1 male, all adults. All had normal or corrected vision, and all volunteered for the experiment, which comprised one session of approximately $45 \mathrm{~min}$. 
Apparatus. The stimuli for the signal detection task are shown in Figure 3. They were drawn on white cards and within $2.5 \mathrm{deg}$ visual angle of the fixation point. All stimuli comprised the same set of line elements-four one-unit lines and eight half-unit lines, plus the target line. The fixation point and surround were as in Experiment 1. The stimuli, again, were designed and presented such that for each orientation, target line segments and both patterns were in the same position in relation to the fixation point, and covering the same area in the subject's visual space.

Procedure. The procedure was the same as that of Experiment 1, the range of exposure times being 24-44 $\mathrm{msec}$.

\section{Results}

Table 1 summarizes the results. A t test for correlated means was performed on the $E_{i}$ : for $N=10$, $\mathrm{p}(\mathrm{t}=-.1477)>.05$. The most probable interpretation of this result is that the absence of depth information nullifies the contextual effect.

\section{EXPERIMENT 3}

There is a body of evidence pointing toward a functional asymmetry of cerebral hemispheres for cognitive processes. In addition to findings of neuroanatomical asymmetries in neonates (Geschwind, 1970; Witelson, 1973) and adults (Witelson, 1973), and psychological studies on clinical patients with unilateral brain lesions (Kimura, 1963; Milner, 1971), a long series of studies on cerebral commissurectomy patients increasingly supports the notion of a basic specialization in hemispheric organization (Gazzaniga, 1972; Sperry, 1973).

Research with normal subjects in audition (Kimura, 1973) and vision (Kimura, 1966; Umilta, Rizzolatti, Marzi, Zambri, Franzini, Camarda, \& Berlucchi, 1974) lends support to the general view that, while the major hemisphere is specialized for verbal and other symbolic functions, the minor hemisphere is associated with spatial form perception and holistic processing in general.

The left visual field (LVF) has been reported superior to the right visual field (RVF) for discrimination of line slopes (Durnford \& Kimura, 1971), rectangular figures oriented at $45 \mathrm{deg}$ from the vertical (Umilta et al., 1974), and for stereoscopic depth perception (Kimura, 1973). The third experiment was designed to replicate in each visual field the finding of Experiment 1 . The hypothesis tested was that the difference in the detectability of a line

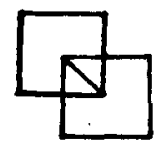

$\mathrm{C}_{1}$

Unitary

left-

oriented
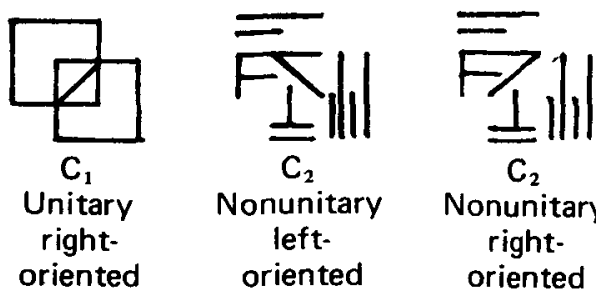

Nonunitary rightoriented
Table 1

Data from $N=10$ Subjects Each for Experiments 1, 2, and 3

\begin{tabular}{|c|c|c|c|}
\hline & $\mathrm{E}_{\mathrm{C1}}$ & $\mathrm{E}_{\mathrm{C2}}$ & $\mathrm{D}$ \\
\hline & \multicolumn{3}{|c|}{ Experiment 1} \\
\hline $\begin{array}{l}\text { Mean } \\
\text { SD } \\
S_{\overline{\mathbf{D}}}\end{array}$ & 2.695 & 1.485 & $\begin{array}{r}1.210 \\
1.270 \\
.402\end{array}$ \\
\hline & \multicolumn{3}{|c|}{ Experiment 2} \\
\hline $\begin{array}{l}\text { Mean } \\
\text { SD } \\
S_{\overline{\mathbf{D}}}\end{array}$ & .946 & .966 & $\begin{array}{r}-.020 \\
.423 \\
.134\end{array}$ \\
\hline & \multicolumn{3}{|c|}{ Experiment 3} \\
\hline $\begin{array}{c}\text { Adjust } \\
\text { RVF } \\
\text { LVF }\end{array}$ & $\begin{array}{l}2.031 \\
1.245\end{array}$ & $\begin{array}{r}.837 \\
1.853\end{array}$ & \\
\hline
\end{tabular}

segment under the two conditions (unitary threedimensional and nonunitary) would be greater in the LVF than in the RVF; and a related falsifiable prediction was that the LVF would show superiority in performance under both unitary and nonunitary conditions.

A signal detection task was again employed, from which four indices, $E_{i}$, could be derived-one each for unitary and nonunitary contexts in each visual field. As before, the target feature was a line segment oriented at $45 \mathrm{deg}$, and the stimuli were designed to be equivalent in the number of constituent segments, area, and position and orientation in the visual space. Cognizance was taken of White's (1969, 1972) criticisms of laterality inferences in visual perception. A verbal response was ruled out, and a bimanual signaling system was employed, also intended to control as far as possible for contralateral hemispheric effects in the initiation of motor activity. The signal detection task required a binary choice, and a monocular test of visual acuity was used to rule out a possible confounding of a laterality difference by ocular acuity dominance (Kershner \& Gwan-rong Jeng, 1972).

\section{Method}

Subjects. The subjects were 10 members of the university community, 8 females and 2 males, all adults. All had normal or corrected vision, and they were paid $\$ 3 / \mathrm{h}$ to take part in the experiment, which comprised one session of approximately $1 \mathrm{~h}$.

Apparatus. The tachistoscopically presented stimuli are shown in Figure 4. For the RVF set, each stimulus pattern was slightly to the right of the fixation point, and for the LVF set slightly to the left of it. When the point is fixated, material in each visual field goes initially to the contralateral hemisphere (Sperry, 1973). The stimuli were designed and presented under the same strictures as in the first two experiments; in addition, the RVF and LVF sets were mirror images within contexts. The monocular visual acuity test was based on the Snellen chart, and was tachistoscopically presented.

Procedure. Conditions were, in general, as those of Experiments 1 and 2, except as noted. Exposure times were in the range of $24-120 \mathrm{msec}$. There were four experimental conditions in a

Figure 3. Stimuli for the signal detection task-Experiment 2. 
Right Visual Field

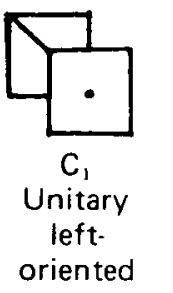

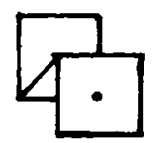

$C_{1}$

Unitary

right-

oriented

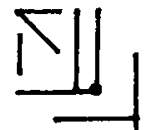

$\mathrm{C}_{2}$ left-

oriented
Nonunitary

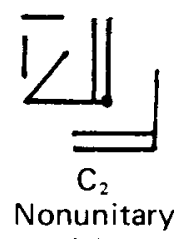

right- oriented

Left Visual Field

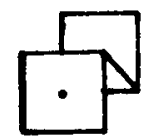

$\mathrm{C}_{1}$

Unitary

left-

oriented

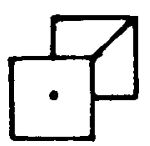

$\mathrm{C}_{1}$

Unitary

right-

oriented

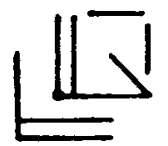

$\mathrm{C}_{2}$

Nonunitary left-

oriented

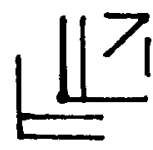

$\mathrm{C}_{2}$

Nonunitary rightoriented
Figure 4. Stimuli for the signal detection task-Experiment 3.

2 by 2 repeated measures design. Each subject had 24 trials on each of the two line orientations under each condition, for a total of 192 trials in irregular order. After completing the main experiment, the subjects were run in the monocular acuity test; each eye was tested separately, and a counting task after the first eye test was used to eliminate any effect of short-term memory of the card for the second eye test.

\section{Results}

The general linear model was applied with an analysis of covariance on the $E_{i}$, the acuity index being treated as a covariate. This index, $A$, was simply the ratio of correct responses for the right eye divided by the number for the left. Table 1 shows the adjusted group means.

Under the conditions of Experiment 3, neither the visual field effect nor the contextual effect is significant at $\alpha=.05$. There is a trend towards an interaction between visual field and context, however, and the results of two orthogonal contrasts show a significant context effect in the RVF, but not in the LVF. The hypotheses of a larger differential in the LVF and of its overall superiority are shown to be untenable. The findings of Durnford and Kimura (1971), therefore, in regard to LVF superiority for line slope detection, are not supported.

\section{DISCUSSION}

Under the conditions of Experiment 3, no overall lateral asymmetry was found for line orientation detection. Levy (1969), however, suggests that while the minor hemisphere abstracts integrated, holistic information, the major hemisphere analyzes stimulus elements for description in language. Given, particularly, the physiological evidence that neurons with receptive field organizations send axons across the corpus callosum (see Sekuler, 1974), form perception probably concerns both hemispheres jointly. On this view, an initial stimulus presentation to the minor hemisphere would produce a shunting to the major hemisphere of information concerning stimulus elements for verbal labeling, while presentation to the major hemisphere would involve transmitting across to the minor information from which spatial properties could be abstracted. The finding of a significant context effect in the RVF only would be interpreted as indicating that under the condition of initial presentation to the major hemisphere, the unitary figural information helps in the line detection task-as compared with the nonunitary information-when this information is combined with the major hemisphere's processing of the target line, while under the other condition-initial presentation to the minor hemisphere-it does not help.

To provide an explanation of the contextual effect, under present paradigms, it seems necessary to refer to a system of feature detection. On rigorous grounds, Sekuler (1974) has shown that a single Hubel and Wiesel type of cell cannot by itself uniquely signal any property to which it responds differentially. While such cells probably play a role in the analysis of stimulus aspects like line orientation, it is as part of a hierarchical system of feature detection. The context effect shows that meaning or structure has consequences for this system, as suggested by Weisstein and Harris (1974). An account of activity in the nervous system associated with such an effect is provided, at least in outline, by Milner (1974), who presents an account of how attentional feedback could operate to influence input. A signal "corresponding" to a centrally facilitated cell assembly fires the assembly, which feeds back to the input via a postulated divergent pathway, running parallel to the ascending convergent pathway. This feedback is ascribed the property of enhancing the activity of cells, causing them to dominate the feature detection networks.

Under this theory, some central representation of the three-dimensional unitary stimulus would provide facilitatory feedback to enhance the detection of the oriented line segment in the detection system. The contextual effect is plausibly retrodictable in that, for the unitary figure, synchronous impulses would facilitate the passage of the signals through the detection system. The problem, however, is that this should also occur in the case of the two-dimensional unitary figure of Experiment 2.

What the percipient seems to be doing in the first experiment is postulating the target line as part of a three-dimensional object. To retain object constancy (cf. Gibson, 1966), the line is seen in perspective, and perhaps weighted in some way during processing such that it is perceived as being longer than the corresponding lines in the nonunitary condition, 
facilitating its detection as a target. The depth effect, on this view, has the consequence of shortening the line for the perceiving organism, who concludes that it is longer than it appears and compensates for the foreshortening on the basis of past experience with three-dimensional objects. An alternative account ${ }^{1}$ along the same lines is that it is the manipulated depth cue alone which is the efficient cause of the difference in detection performance between Experiments 1 and 2, the unity or "goodness" of the figures being incidental to it. This could be tested, if one could devise a nonunitary figure containing a depth cue.

While three-dimensionality seems the most probable agent of the context effect, other possibilities, such as effects of contour proximity, cannot be completely ruled out by the stimuli employed in these experiments. The context effect, however, can be taken as support for the Gestalt, as opposed to the information-processing, approach to the question of form perception.

\section{REFERENCES}

DLRNFORD. M.. \& KIMCRA. D. Right hemisphere specialization tor depth perception retlected in visual field differences. Nature. $19^{-1}$ 1. 231. 394-395.

Gazzeviga. M. One brain-two minds? American Scientist. 1972. 60. $311-31^{-}$.

Geschwisd, $N$. The organization of language and the brain. Science, $19^{-0} 0.170 .940-944$.

GiBsox. J. J. The senses considered as perceptual systems. Boston: Houghton-Mifflin. 1966.

HABER. R. N.. \& HeRSHENSON. M. The psychology of visual perception. New York: Holt. Rinehart. \& Winston. 1973.

HLbEL. D. H. \& WIESEL. T. N. Receptive fields. binocular interaction and functional architecture in the cat's risual cortex. Journal of Physiologi. 1962. 160. 106-154.

HLbel. D. H. \& W Wiesel. T. N. Receptive fields and functional architecture in two non-striate visual areas (18 and 19) of the cat. Journal of Neurophysiolog:. 1965. 28. 229-289.

Hubel. D. H. \& Wiesel. T. N. Receptive fields and functional architecture of monkey striate cortex. Joumal of Physiology. 1968. 195. 215-243.

Kershier. J. A.. \& Gwan-rong Jeng. A. Dual functional hemispheric asymmetry in risual perception: Effects of ocular dominance and post-exposural processes. Neuropsychologia. 19-2. 10. $431 \cdot 445$.
Kimura. D. Right temporal lobe damage: Perception of unfamiliar stimuli after damage. A rchives of Neurology. 1963. 8, 264-271.

Kimera. D. Dual functional asimmetry of the brain in visual perception. Neuropsychologia. 1966. 4. 2-5-285.

Kimura. D. The astmmetry of the human brain. Scientific American, 19-3, 228, 70-78.

LEVY. J. Possible basis for the evolution of lateral specialization in the human brain. Nature, 1969. 224. 614-615.

MitNer. B. Interhemispheric differences in the localization of psychological processes in man. British Medical Bulletin. 1971. 27. 2־2-27?.

Milner. P. M. A model for visual shape recognition. Psichological Review: 19\%. 81.521 .535 .

NaChmias. J. Signal detection theory and its application to problems in vision. In D. Jameson \& L. M. Hurvich (Eds.). Handbook of senson physiology (Nol. 4). Berlin: Springer Verlag. 1974.

Neisser. U. Cognitive psychology. New York: Appleton-Century. Crofts. $196^{-}$

Seklter. R. Spatial vision. In Annual Review of Psychology. Palo Alto. Calif: Annual Reviews. 197.

Selfridge. O. G. Pandemonium: A paradigm for learning. In The mechanization of thought processes. London: H. M. Stationery Office. 1959.

Simpson. A. J. \& Fitter, M. J. What is the best index of detectability? Psichological Bulletin. 19-3. 80. 481-488.

SPERRY. R. W. Lateralization of cerebral function in the surgically separated hemispheres. In F. J. MeGuigan \& R. A. Schoonover (Eds.). The psychophysiology of thinking. New York: Academic Press. $19^{-} 3$.

Umilta. C.. Rizzolatti. G.. Marzi. C. A.. Zambri, G.. Fravizini, C.. Camarda, R. \& Berlecchi. G. Hemispheric differences in the discrimination of line orientation. Neuropsichologia. 19-4. 12, 165-1-7.

Weissteix. N.. \& HarRis. C. Visual detection of line segments: An object superiority effect. Science. 1974, 186. $752-755$.

WhITE, M. J. Laterality differences in perception: A review. Psychological Bulletin, 1969, 72, 387,-405.

WhITE. M. J. Hemispheric asymmetries in tachistoscopic information processing. British Journal of Psychology. 1972. 63. $49^{-}-508$.

Witelsos. S. Left hemisphere specialization for language in the newborn: Neuroanatomical evidence of astmmetry. Brain. 1973. 96. $6+1-6+6$.

\section{NOTE}

1. I am indebted to Stanley Coren and Lawrence Ward for this suggestion.

(Received for publication December 13, 1975; revision accepted September 14, 1976.) 